\title{
Hardness evaluation of dental composites fabricated from the uniform size and well-distributed zirconia-alumina-silica fillers with sol-gel technique
}

\author{
Muhamad Lukman Nur Hakim*, Zulia Hasratiningsih**, Nina Djustiana**, Bambang \\ Sunendar***, \#YYanwar Faza** \\ * Tokushinkai Dental, Suzhou, Jiangsu, China \\ **Department of Dental Materials Science and Technology Faculty of Dentistry Universitas \\ Padjadjaran, Indonesia \\ ***Department of Engineering Physics Faculty of Industrial Technology, Bandung Institute of \\ Technology, Indonesia
}

\begin{abstract}
Introduction: Several factor limits of services of dental composite have triggered further improvement. $\mathrm{ZrO}_{2}-\mathrm{Al}_{2} \mathrm{O}_{3}-\mathrm{SiO}_{2}$ system as filler of dental composite had been developed with sol-gel technique. Ultrasonic homogeniser were reported to change the particle size ditribution or shape. Unifom size and distribution of particle is believed to help define the behavior of hardness properties. Methods: The study was an laboratory experimental design. Filler $\mathrm{ZrO}_{2}-\mathrm{Al}_{2} \mathrm{O}_{3}-\mathrm{SiO}_{2}$ system were developed via sol-gel methods. Post calcination process, filler were immerse in ethanol and applied with ultrasonic homogeniser, with various amplitude i.e $50 \mathrm{rpm}, 60 \mathrm{rpm}$ and $80 \mathrm{rpm}$ then named sample A, B, and C. XRD, SEM anda PSA were used to characterize of filler system. Subsequent filler were used to fabricate dental composite then evaluate the hardness value using micro-hardness tester. One-way ANOVA was used to analysis the statistical result of hardness value. Results: XRD pattern of three sample were similar in which tetragonal zirconia was prominent (57-61 \%) followed by monoclinic zirconia (24-25\%) and amorphous (15-17 \%). While, SEM and PSA characterization showed amplitude $50 \mathrm{rpm}$ (sample A) produce more uniform size and well-distributed particle filler than the others. In contrary, sample B and C showed higher peak in PSA results. It means there was dominating of filler with particular size. However, the hardness value did not show significant differences between those filler $(p>0,05)$. Conclusion: Dental composite that contain of different uniformity and distribution of filler $\mathrm{ZrO}_{2}-\mathrm{Al}_{2} \mathrm{O}_{3}-\mathrm{SiO}_{2}$ system has no significantly differences of hardness value.
\end{abstract}

Keywords: Dental composite, hardness value, ultrasonic homogeniser, uniform size and distribution of particle, sol-gel technique.

p-ISSN: 1979-0201; e-ISSN: 2549-6212; Available from: http://jurnal.unpad.ac.id/pjd/editor/submission/18319

DOI: http://dx.doi.org/10.24198/pjd.vol30no2.18319

Submission: February 6, 2018; Accepted: June 8, 2018; Published online: July 31, 2018

\#Corresponding author: Yanwar Faza, Department of Dental Materials Science and Technology, Faculty of Dentistry, Universitas Padjadjaran, Indonesia

Sekeloa Selatan I, Bandung 40132, Indonesia. Phone: +62 813-2281-4654. E-mail: faza.yanwar@gmail.com 


\section{INTRODUCTION}

Dental restoration had been developed since centuries. Materials used to fabricate dental restoration are coming from metal, polymer, ceramic, and composite. ${ }^{1,2}$ Metal is the first material used for dental restoration that possess high strength. ${ }^{3,4}$ Due to the unaesthetic color, it was abandoned. Polymer (unfilled resin) is the former aesthetic restoration in dentistry. ${ }^{5}$ However, insufficient mechanical properties, limit its application for dental restoration. Combination of ceramic and resin polymer, known as dental composite, improve the aesthetic and mechanical properties of the dental restoration at the same time..$^{1,6,7}$

Dental composite consist of resin matrix, filler, coupling agent, initiator and accelerator system (polymerization). ${ }^{8}$ Filler is a component that may affect the characteristic of dental composite. ${ }^{9,10}$ Zirconia, alumina and silica were frequently used as a composite filler. ${ }^{11}$ Zirconia possesses high strength due to the ability of transformation toughening. It require stabilization of its tetragonal crystalline to gain such ability. ${ }^{12}$ Alumina, having the highest hardness value amongs ceramic, is one of the metal oxide that can be used as stabilizer for zirconia. ${ }^{13}$ Beside, Silica has lower mechanical properties, but owning the outstanding of translucency. ${ }^{11}$

Good dispersion and good particle size distribution (uniform size) of filler ceramic within dental composite may effect the properties of dental composite. ${ }^{9}$ ultrasonic homogenizer has been reported can retarded precipitation, change crystal character and change the particle size distribution or shape. ${ }^{14}$ Previous study had produce filler ceramic $\mathrm{ZrO}_{2}-\mathrm{Al}_{2} \mathrm{O}_{3}-\mathrm{SiO}_{2}$ system using solgel technique. However, the study just applied particular amplitude of ultrasonic homogenizer to obtain nano meter size of the filler ceramic and well dispersion. Hardness test is one of properties that is easy to conduct and well correlated with others mechanical properties.11,13,15 This study propose to evaluate the hardness value of dental composite that made from uniform size and well-distributed filler ceramic $\mathrm{ZrO}_{2}$ $\mathrm{Al}_{2} \mathrm{O}_{3}-\mathrm{SiO}_{2}$ system with sol-gel technique.

\section{METHODS}

Zirconium chloride $\left(\mathrm{ZrCl}_{4}\right)$, Aluminium nitrate $\left(\mathrm{Al}\left(\mathrm{NO}_{3}\right)^{3}\right)$ and Tetraethyl orthosilicate (TeOS) were used as precursor to develop $\mathrm{ZrO}_{2}-\mathrm{Al}_{2} \mathrm{O}_{3}$ $\mathrm{SiO}_{2}$ system with sol-gel process. The ratio of three precursor was $80: 9: 11$ respectively. Urethane dimethacrylate (UDMA), Triethylene glycol dimethacrylate (TEGDMA) and Hydroxyethyl methacrylate (HEMA) were used as monomer resin. Champorquinone (CQ) and 2-(dimethylamino) ethyl methacrylate (DMAEMA) were used as photointiator and co-iniator consecutively. Materials mentioned above were purchased from Sigma-Aldrich Company.

In beginning of sol-gel process, the precursors were hydrolyzed one by one while keep stirring for 60 minutes up to well homogenized. The mixture was heated in the oven at $110^{\circ} \mathrm{C}$ for ageing process. Subsequently, it was calcined in the furnace at $600^{\circ} \mathrm{C}$ to solidify the ceramic system. Acquired filler ceramic $\mathrm{ZrO}_{2}-\mathrm{Al}_{2} \mathrm{O}_{3}-\mathrm{SiO}_{2}$ were then immersed in ethanol $96 \%$ continue with applying the ultrasonic homogenizer with various amplitude $50 \mathrm{rpm}, 65 \mathrm{rpm}$ and $80 \mathrm{rpm}$ then named as sample $A, B$ and $C$ respectively. Furthermore, throughout samples were covered with perforated aluminium foil and dried overnight in the oven at $80^{\circ} \mathrm{C}$.

Filler $\mathrm{ZrO}_{2}-\mathrm{Al}_{2} \mathrm{O}_{3}-\mathrm{SiO}_{2}$ system in sample $A, B$ and $C$ were coated with chitosan $1 \%$ prior to fabricate three dental composite based upon the filler. In fabrication, the filler-chitosan were gradually poured in the mixture of monomer resins, photoinitiator and co-initiator until pastelike consistency obtained. The paste were placed in cylindrical mold $(3.0 \pm 0.1 \mathrm{~mm}$ in height and 6.0 $\pm 0.1 \mathrm{~mm}$ in diameter) and cured by LED device. 15 cylindrical speciment were fabricated with each of 5 speciment per group.

Morphology and partcle size of filler $\mathrm{ZrO}_{2}$ $\mathrm{Al}_{2} \mathrm{O}_{3}-\mathrm{SiO}_{2}$ were analysed by Scanning Electron Microscopy and its crystalinity were analyzed by $X$-Ray difrraction spectroscopy. Size distribution volume of the filler were analyzed by particle size analysis. Dental composite made from filler $\mathrm{ZrO}_{2}-\mathrm{Al}_{2} \mathrm{O}_{3}-\mathrm{SiO}_{2}$ were tested using micro-Vickers hardness tester machine, LECO - Japan M - 400 - 

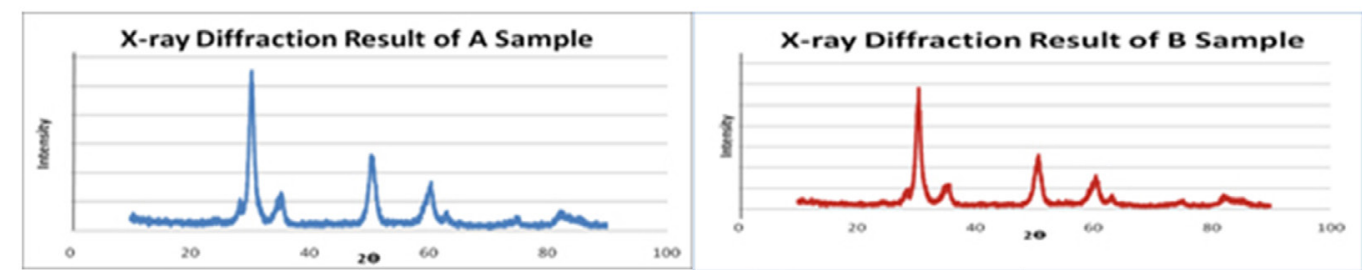

X-ray Diffraction Result of C Sample

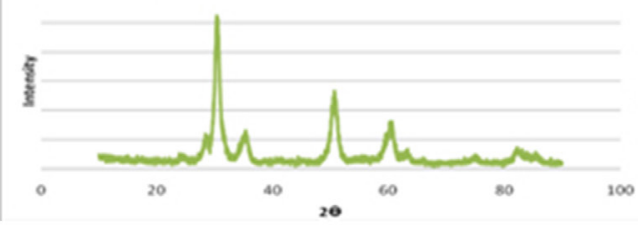

Figure 1. XRD characterisation results with no significant diffrent pattern amongst three samples
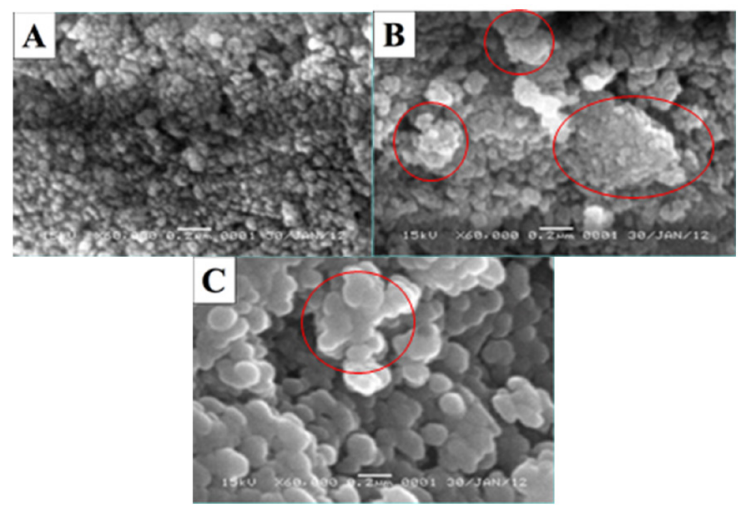

Figure 2. SEM characterisation showed well-

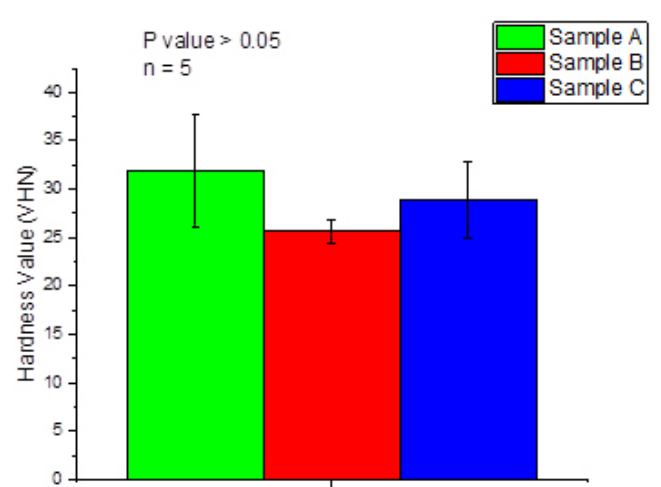

Figure 4. No significant hardness value difference amongst three samples distributed filler particle in sample A; Agglomeration (shown in red circle) shown in sample B; Sample C showed less agglomeration.

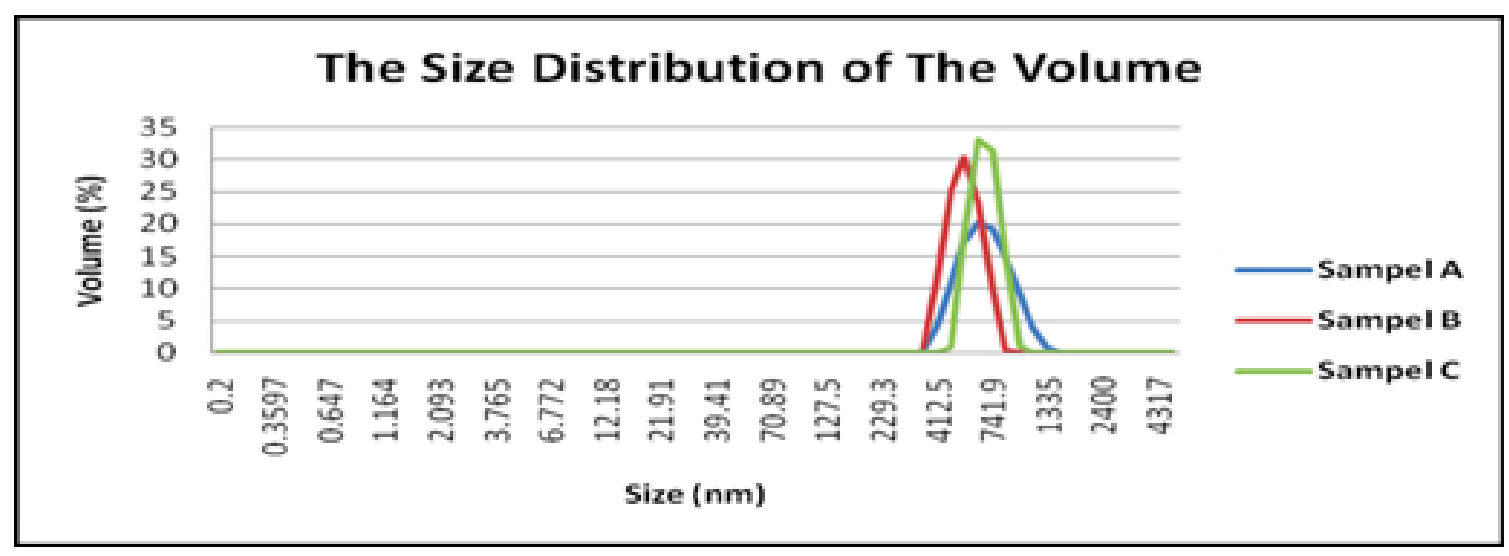

Figure 3. PSA characterisation results 
$\mathrm{H} 1 / \mathrm{H} 2 / \mathrm{H} 3$ with a load of 200 grams for 15 seconds (ADA Specification No. 27). Hardness results were statistically analysed using one-way ANOVA test, at significant level of $5 \%$.

\section{RESULTS}

XRD patterns of filler $\mathrm{ZrO}_{2}-\mathrm{Al}_{2} \mathrm{O}_{3}-\mathrm{SiO}_{2}$ system, in which treated with different amplitude of ultrasonic homogenizer, as shown in Figure 1. There are no obvious differences in XRD patterns between sampel $A, B$ and $C$. They exhibit the weigth fraction of crystallinity of tetragonal zirconia, monoclinic zirconia, and amorphous are $57-61 \%, 24-25 \%$, and $15-17 \%$ respectively. Analysis $\mathrm{X}$-powder software from the patterns reveal an average size of crystalline of $\mathrm{ZrO}_{2}-\mathrm{Al}_{2} \mathrm{O}_{3}$ $\mathrm{SiO}_{2}$ system were $7.56 \mathrm{~nm}, 8.56 \mathrm{~nm}$, and $7.64 \mathrm{~nm}$ for sample $A, B$, and $C$ consecutively.

The SEM results of the three samples showed the grain size and relative distribution of filler particle. Most of them show particle size in submicron. For description of particle distributon, sample $A$ is spreading very well than the others. Agglomeration is clearly viewed in sample B, however, less viewed in sample $C$ and $A$.

The PSA characterisation show sample A has the lowest and broader peak. It means, the distribution of the particles possess same volume and no dominating size. In contrary for sample $B$ and $C$, the peaks more are higher and narrow than sample A. particle size shown in range 200 nanometer to 1335 nanometer.

Mechanical tests performed by the microVickers hardness tester showed there are no significantly differences between each sample of dental composite containing different categorize of filler.

\section{DISCUSSION}

According to XRD spectra on Figure 1 tetragonal zirconia crystalline (JCPDS 14-0534) is the highest fraction of crystalline followed by monoclinic zirconia (JCPDS 37-1484) and amorphous silica. It is known that alumina may stabilize tetragonal crystallin of zirconia in room temperature. ${ }^{12,16}$ Hydrolysis of $\mathrm{Al}\left(\mathrm{NO}_{3}\right)_{3}$ may discharge anion $\mathrm{NO}^{3-}$ then react with hydrolysis product of $\mathrm{ZrCl}_{4}$. The anion retain within zirconia lattice and prevent the passage of oxygen ion when cooling down. Therefore it hinder the tetragonal-monoclinic transfromation. The present of anion $\mathrm{NO}^{3-}$ also inhibit the escape of $-\mathrm{OH}$ group of filler during calcination. It cause enhancement stability of tetragonal zirconia as well. ${ }^{12,17}$ However, the amount of tetragonal crystalline is not high enough (57\% - 61\%) in sample A, B and C. It suspect due to lower content of alumina that insufficient to obtain fully tetragonal crystalline. ${ }^{12}$

Morphology of particle ceramic shown in Figure 2, were viewed different between three samples. Sample A show more uniform size and well distribution of particle filler then sample $B$ and $C$. While, aglomeration are present in sample $B$ and $C$. Fillers is major determinant of mechanical properties of dental composite. They act as a toughening agent via stress distribution. Instead of volumetric fraction and particle shape of filler, uniform particle size and distribution of filler were contribute to define the behavior of dental composite. ${ }^{18,19}$

SEM characterisation result are consistent with the PSA analysis in Figure 3. Sample A, with amplitude of ultrasonic homogeniser $50 \mathrm{rpm}$, proven broader and lowest peak. It means there are no dominating particle size. It proven the homogenity of particle size of filler of sample $A$ is the finest one. However, sample $B$ shown higher peak followed by sample $C$ as the highest. It means there is particular size of particle filler dominate among the others. During ultrasonic homogenizer process, the longer process causing more vibration of the wave received by the sample and produce smaller size and evenly distributed particle. ${ }^{20}$

The particle size and distribution of filler affect the strength and hardness of the sample. Along with the filler, coupling agent is also play important role to link the filler with resin matrix. Chitosan $1 \%$ had been used as coupling agent for filler $\mathrm{ZrO}_{2}-\mathrm{Al}_{2} \mathrm{O}_{3}-\mathrm{SiO}_{2}$ system. The amino group of chitosan is predicted to create bonding between filler and resin matrix. ${ }^{8,13}$ Micro-Vickers hardness in Figure 4 shows means value of sample $A, B$, and $\mathrm{C}$ were $31.9 \mathrm{VHN}, 25.63 \mathrm{VHN}$ and $28,9 \mathrm{VHN}$ respectively. However, there was no significant 
differences of hardness value ( $p$-value $>0.05)$ between those samples.

\section{CONCLUSION}

Different amplitudes during the ultrasonic homogenization process produce differences in sizes and distribution of filler $\mathrm{ZrO}_{2}-\mathrm{Al}_{2} \mathrm{O}_{3}-\mathrm{SiO}_{2}$ system. However, there are no differences of hardness value of the dental composite acquired from those filler. Hardness value is still insufficient to be posterior restoration. Further research with different silane coupling agent is necessary to be done.

\section{REFERENCES}

1. Anusavice KJ. Phillip's science of dental material. 12st ed. St. Louis: Saunders-Elsevier; 2013. p. 30-47.

2. Powers JM, Wataha JC. Dental Materials: Properties and Manipulation. 10th ed. St. Louis: Mosby; 2012. p. 68-124, 232-57.

3. Fokkinga WA, Kreulen CM, Le Bell-Rönnlöf AM, Lassila LV, Vallittu PK, et al. In vitro fracture behavior of maxillary premolars with metal crowns and several post-and-core systems. Eur J Oral Sci. 2006; 114(3): 250-6. DOI: 10.1111/j.1600-0722.2006.00357.x

4. Wagner WC, Chu TM. Biaxial flexural strength and indentation fracture toughness of three new dental core ceramics. J Prosthet Dent. 1996; 76(2): 140-4. DOI: 10.1016/500223913(96)90297-8

5. Azzopardi N, Moharamzadeh K, Wood DJ, Martin N, van Noort R. Effect of resin matrix composition on the translucency of experimental dental composite resins. Dent Mater. 2009; 25(12): 1564-8. DOI: 10.1016/j. dental.2009.07.011

6. Haselton DR, Diaz-Arnold AM, Hillis SL. Clinical assessment of high-strength all-ceramic crowns. J Prosthet Dent. 2000; 83(4): 396-401.

7. Höland W, Schweiger M, Watzke R, Peschke A, Kappert $\mathrm{H}$. Ceramics as biomaterials for dental restoration. Expert Rev Med Devices. 2008; 5(6): 729-45. DOI: 10.1586/17434440.5.6.729

8. Djustiana N, Greviana N, Faza Y, Sunarso. Synthesis and characterization of dental composites. AlP Conference Proceedings. 2018; 1927: 020003. DOI: 10.1063/1.5021191

9. Xavier TA, Fróes-Salgado NRG, Meier MM, Braga RR. Influence of silane content and filler distribution on chemical-mechanical properties of resin composites. Braz Oral Res. 2015; 29(1): 1-8. DOI: 10.1590/1807-3107BOR2015.vol29.0072

10. Amdjadi P, Ghasemi A, Najafi F, Nojehdehian $\mathrm{H}$. Pivotal role of filler / matrix interface in dental composites: Review. Biomed Res. 2017; 28(3): 1054-65.

11. Hasratiningsih Z, Cahyanto A, Takarini V, Karlina E, Usri K, Febrida R, et al. Basic Properties of PMMA Reinforced Using Ceramics Particles of ZrO2-Al2O3-SiO2 Coated with Two Types of Coupling Agents. Key Eng Mater. 2016; 696: 93-8. DOI: 10.4028/www.scientific. net/KEM.696.93

12. Faza $Y$, Hasratiningsih Z, Harmaji A, Joni IM. Preparation and characterization of zirconiaalumina system via solution and solid phase mixing method. AIP Conference Proceedings. 2018; 1927: 030030. DOI: 10.1063/1.5021223

13. Hasratiningsih Z, Takarini V, Cahyanto A, Faza A, Asri LATW, Purwasasmita BS. Hardness evaluation of PMMA reinforced with two different calcinations temperatures of $\mathrm{ZrO2}$ Al2O3-SiO2 filler system. IOP Conference Series: Material Science and Engineering. 2017; 172: 012067. DOI: 10.1088/1757899X/172/1/012067

14. Nishida I. Precipitation of calcium carbonate by ultrasonic irradiation. Ultrasonics Sonochem. 2004; 11(6): 423-8. DOI: 10.1016/j. ultsonch.2003.09.003

15. Abed YA, Sabry HA, Alrobeigy NA. Degree of conversion and surface hardness of bulk-fill composite versus incremental-fill composite. Tanta Dent J. 2015; 12(2): 71-80. DOI: 10.1016/j.tdj.2015.01.003

16. Bergmann CP, Stumpf A. Dental Ceramics: Microstructure, Properties, and Degradation. Berlin: Springer-Heidelberg; 2013.

17. Stefanic G, Music S. Factors Influencing the Stability of Low Temperature Tetragonal ZrO2. Croat Chem ACTA. 2002; 75(3): 727-67.

18. Klapdohr S, Moszner N. New Inorganic Components for Dental Filling Composites. 
Chem Monthly. 2005; 136(1): 21-45. DOI: 10.1007/s00706-004-0254-y

19. Fujita K, Ikemi T, Nishiyama N. Effects of particle size of silica filler on polymerization conversion in a light-curing resin composite. Dent Mater. 2011; 27(11): 1079-85. DOI: 10.1016/j.dental.2011.07.010

20. Asada C, Doi K, Sasaki C, Nakamura Y. Efficient Extraction of Starch from Microalgae Using Ultrasonic Homogenizer and Its Conversion into Ethanol by Simultaneous Saccharification and Fermentation. Nat Resources. 2012; 3: 175-9. DOI: $10.4236 / \mathrm{nr} .2012 .34023$ 